Supporting Information for

\title{
Reaction Kinetics and Transformation of Carbadox and Structurally Related Compounds with Aqueous Chlorine
}

\author{
Amisha D. Shah, Jae-Hong Kim, and Ching-Hua Huang* \\ School of Civil and Environmental Engineering, Georgia Institute of Technology \\ Atlanta, Georgia 30332 \\ *Corresponding author phone: (404) 894-7694; fax: (404) 894-8266; e-mail: ching- \\ hua.huang@ce.gatech.edu
}

Author e-mail: amisha.shah@ce.gatech.edu

Text S1. Chemical reagents, stock solutions, and surface water samples.

Text S2. Assessing the effect of $\mathrm{Na}_{2} \mathrm{~S}_{2} \mathrm{O}_{3}$ quenching agent on the observed CDX kinetics.

Text S3. Experimental setup for reaction of CDX with free chlorine in $\mathrm{H}_{2}{ }^{18} \mathrm{O}$ at $\mathrm{pH} 9$.

Text S4. Results for CDX loss at low and neutral/high $\mathrm{pH}$ without oxidant addition.

Text S5. DAD detection wavelengths, HPLC mobile phase conditions, and MS parameters.

Figure S1. CDX/DCR competition kinetics.

Figure S2. DCDX/CDX competition kinetics.

Figure S3. Model $k_{\text {app }}{ }^{\mathrm{CDX}}$ fittings with varying $k_{1}$.

Figure S4. Spectra of CDX chlorination by-products.

Figure S5. Spectra of DCDX chlorination by-products.

Figure S6. DCDX product evolution under excess free chlorine conditions at pH 5.2, 7.5, and 8.9.

Figure S7. CDX products formed with and without acetate addition.

Figure S8. $\mathrm{CDX}-\mathrm{Cl}$ product formed upon $\mathrm{NaCl}$ addition 
Text S1. Chemical Reagents: CDX, QX, QNO, and 4,6-dichlororesorcinol (DCR) from SigmaAldrich, and ODX from MP Biomedicals were at $\geq 97 \%$ purity. DCDX, QDX, and QXO were synthesized from methods described previously (1). $\mathrm{H}_{2}{ }^{18} \mathrm{O}$ was obtained from Cambridge Isotope Laboratories at $>97 \%$ purity. $\mathrm{NaOCl}$ was obtained from Fisher Scientific at $\sim 5 \%$ solution concentration. All other chemicals were of reagent grade or higher and used directly without further purification. Reagent water $\left(18.2 \mathrm{M} \Omega-\mathrm{cm}\right.$ at $\left.25^{\circ} \mathrm{C}\right)$ was prepared from a Millipore water purification system.

Stock Solutions: Stock solutions for CDX, DCDX, ODX, QDX, QXO and QNO were prepared at 25$50 \mathrm{mg} / \mathrm{L}$ in $50 / 50 \%(\mathrm{v} / \mathrm{v})$ methanol/water. Stock solutions for QX and DCR were prepared at $100 \mathrm{mg} / \mathrm{L}$ in $10 / 90 \%$ (v/v) methanol/water and pure methanol, respectively. Stock solutions were stored at $\sim 4^{\circ} \mathrm{C}$ and used for up to two months. Free chlorine concentrations were prepared at $100 \mathrm{mg} / \mathrm{L}$ (kinetic experiments) and $500 \mathrm{mg} / \mathrm{L}$ (by-product assessment experiments) as $\mathrm{Cl}_{2}$ and were monitored using the standard iodometric titrimetric method (2).

Surface Water Samples: Source water was first collected from the Chattahoochee river (Cochran Shoals/ Power Island, Chattahoochee River National Recreation Area) in the greater Atlanta, GA, USA region. Source water was stored at $\sim 4^{\circ} \mathrm{C}$ upon arrival, filtered through a $0.45 \mu \mathrm{m}$ glass fiber filter, and used within 24 hours from time of collection. Non-purgeable organic carbon was measured using a Shimadzu TOC-Vws analyzer.

Residual free chlorine was measured for these source water samples using the standard DPD/FAS titrimetric method (2) and found to not persist at $>18.0 \mu \mathrm{g} / \mathrm{L}$ as $\mathrm{Cl}_{2}$ (method detection limit). Levels of residual free chlorine and combined chlorine were also measured using the standard DPD/FAS titrimetric method (2) upon addition of free chlorine to surface water samples in order to measure potential formation of $\mathrm{NH}_{2} \mathrm{Cl}$ and $\mathrm{NHCl}_{2}$. Given an initial free chlorine dose of $14.2 \mathrm{mg} / \mathrm{L}$ as $\mathrm{Cl}_{2}$ 
$(0.2 \mathrm{mM})$ spiked into pure surface water (dose is equivalent to CDX reaction conditions), $11.9 \mathrm{mg} / \mathrm{L}$ as $\mathrm{Cl}_{2}$ residual total chlorine was found, of which $92.1 \%, 3.8 \%$, and $4.6 \%\left(\mathrm{mg} / \mathrm{L}\right.$ as $\left.\mathrm{Cl}_{2}\right)$ were free chlorine, $\mathrm{NH}_{2} \mathrm{Cl}$, and $\mathrm{NHCl}_{2}$, respectively.

Text S2. To determine the effect of the quenching agent, $\mathrm{Na}_{2} \mathrm{~S}_{2} \mathrm{O}_{3}$, on the observed kinetic rates for CDX, excess free chlorine $(100 \mathrm{mM})$ was added to $\mathrm{CDX}(10 \mathrm{mM})$ that was previously buffered to $\sim \mathrm{pH}$ 4. One sample was aliquoted and directly injected into the HPLC at 2 min $53 \mathrm{~s}$ without addition of $\mathrm{Na}_{2} \mathrm{~S}_{2} \mathrm{O}_{3}$. A second sample was aliquoted and quenched at the same rxn time (2 min $\left.53 \mathrm{~s}\right)$ and placed on the HPLC for analysis. CDX peak area was compared between the quenched and unquenched sample. Results indicate that $>50 \%$ of CDX in both samples had reacted, and the difference in peak area between the unquenched and quenched sample was $<5.5 \%$, confirming that $\mathrm{Na}_{2} \mathrm{~S}_{2} \mathrm{O}_{3}$ addition did not convert any intermediates back to the parent CDX.

Text S3. Batch experiments were also conducted for $\mathrm{CDX}$ reaction with free chlorine in $\mathrm{H}_{2}{ }^{18} \mathrm{O}$ at $\mathrm{pH} 9$. CDX was added at $26 \mu \mathrm{M}$ from a $25 \mathrm{mg} / \mathrm{L}$ pure methanol stock solution, and $10 \mathrm{mM}$ sodium borate was added directly to $\mathrm{H}_{2}{ }^{18} \mathrm{O}$ to achieve $\mathrm{pH} \sim 9$. Final $\mathrm{H}_{2}{ }^{16} \mathrm{O}$ interference was $<3.5 \%$. Excess free chlorine $(260 \mu \mathrm{M})$ was added to initiate the reaction but was not quenched. After 10-12 min, the reaction mixture was injected into the HPLC/DAD/MS for analysis.

Text S4. Batch experiments were conducted without oxidant for CDX at low pH (50 mM phosphate buffer at $\mathrm{pH} 2.5-3$ or acetate buffer at $\mathrm{pH} 4)$ and neutral/high $\mathrm{pH}(50 \mathrm{mM}$ phosphate buffer at $\mathrm{pH} 7$ or borate buffer at $\mathrm{pH} 9-11$ ) conditions to assess potential hydrolysis. At $\mathrm{pH} 7.21$, only 5.3\% pf CDX loss was observed over a reaction time of 336 hrs (14 days). At pH 8.83, 31.1\% loss was observed over 
a reaction time of $288 \mathrm{hrs}$ (12 days), and therefore exact $k_{\mathrm{obs}}$ values could not be obtained. An approximate $k_{\mathrm{obs}}$ value of $2.8 \times 10^{-7} \mathrm{~s}^{-1}$ at $\mathrm{pH} 8.83$ was found. At $\mathrm{pH} 10.38, k_{\mathrm{obs}}$ was $1.64 \times 10^{-6} \mathrm{~s}^{-1}$. All high $\mathrm{pH}$ experiments described here were conducted in duplicate. At low $\mathrm{pH}$ from 2.81 to 4.04, no reactions achieved greater than 50\% loss after $287 \mathrm{hrs}$ (11 days and $23 \mathrm{hrs}$ ). Therefore, $k_{\mathrm{obs}}$ values for $\mathrm{pH} 2.81,3.02$, and 4.04 were only approximated at $5.65 \times 10^{-7}, 3.92 \times 10^{-7} \mathrm{~s}^{-1}, 1.22 \times 10^{-7} \mathrm{~s}^{-1}$, respectively.

Text S5. DAD Detection Wavelengths: Detection wavelengths for CDX, DCDX, QX, QDX and DCR were 308, 280, 235, 250, and $295 \mathrm{~nm}$, respectively. Detection wavelengths for QXO and QNO were $230 \mathrm{~nm}$.

Analysis of CDX and Structurally Related Compounds (Batch Experiments): The mobile phase for all compounds studied consisted of a $20 \mathrm{mM}$ acetic acid solution with $5 \%$ acetonitrile (eluent A) and acetonitrile (eluent B). The mobile phase started at 5\% B (95\% A), increased to $15 \% \mathrm{~B}$ in $5 \mathrm{~min}, 23 \% \mathrm{~B}$ in $20 \mathrm{~min}$, and $95 \% \mathrm{~B}$ from 21-25 min. An additional period of 100\% B from 27-30 min was used in DCDX analysis.

Analysis of CDX, DCDX, and DCR (Competition Kinetic Experiments): The mobile phase for simultaneous CDX and DCR analysis consisted of a $20 \mathrm{mM}$ acetic acid solution with 5\% acetonitrile (eluent A) and methanol (eluent B) in which the gradient started and remained at 40\% B (60\% A) for 5 min, increased to $75 \% \mathrm{~B}$ at $10 \mathrm{~min}, 95 \%$ at $12 \mathrm{~min}$, and $100 \% \mathrm{~B}$ from $17-20 \mathrm{~min}$. Simultaneous detection of DCDX and CDX used the same mobile phase for DCDX in batch experiments. MS Parameters: MS analysis was conducted by electrospray ionization in positive mode at both low and high fragmentation voltages $(80$ and $220 \mathrm{eV})$ to yield optimal low and high fragmentation patterns with a mass scan range of $\mathrm{m} / \mathrm{z}, 100-1000$. The drying gas was at $10 \mathrm{~L} / \mathrm{min}$ at $350^{\circ} \mathrm{C}$, the nebulizer pressure 25 psig, and the capillary voltage $4000 \mathrm{~V}$. 
Figure S1. Competitional loss of CDX/DCR with varying substoichiometric amounts of free chlorine to determine $k_{\mathrm{app}}^{\mathrm{DCR}} / k_{\mathrm{app}}{ }^{\mathrm{CDX}}$ at $\mathrm{pH} 6.18-10.65$ and $25^{\circ} \mathrm{C}$.

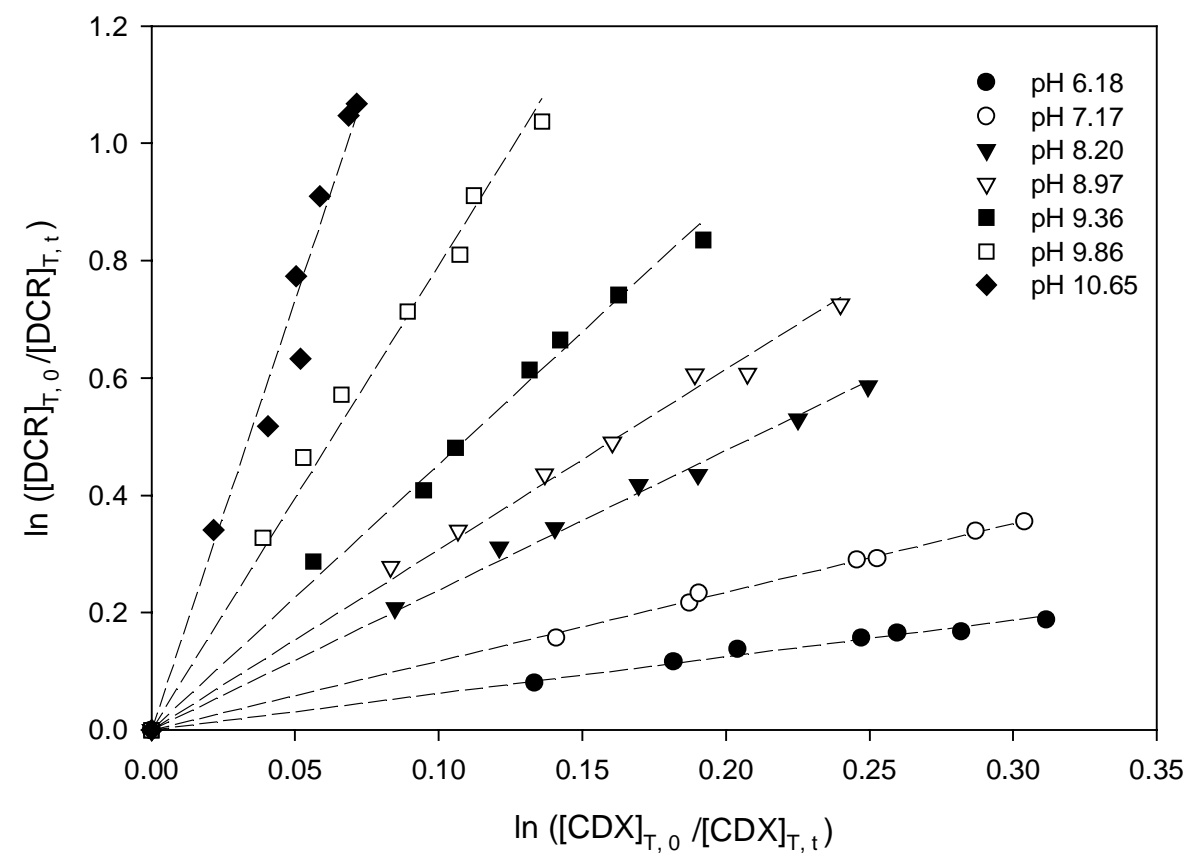

Figure S2. Competitional loss of DCDX/CDX with varying substoichiometric amounts of free chlorine to determine $k_{\text {app }}{ }^{\mathrm{CDX}} / k_{\text {app }}{ }^{\mathrm{DCDX}}$ at $\mathrm{pH} 6.25-10.65$ and $25^{\circ} \mathrm{C}$.

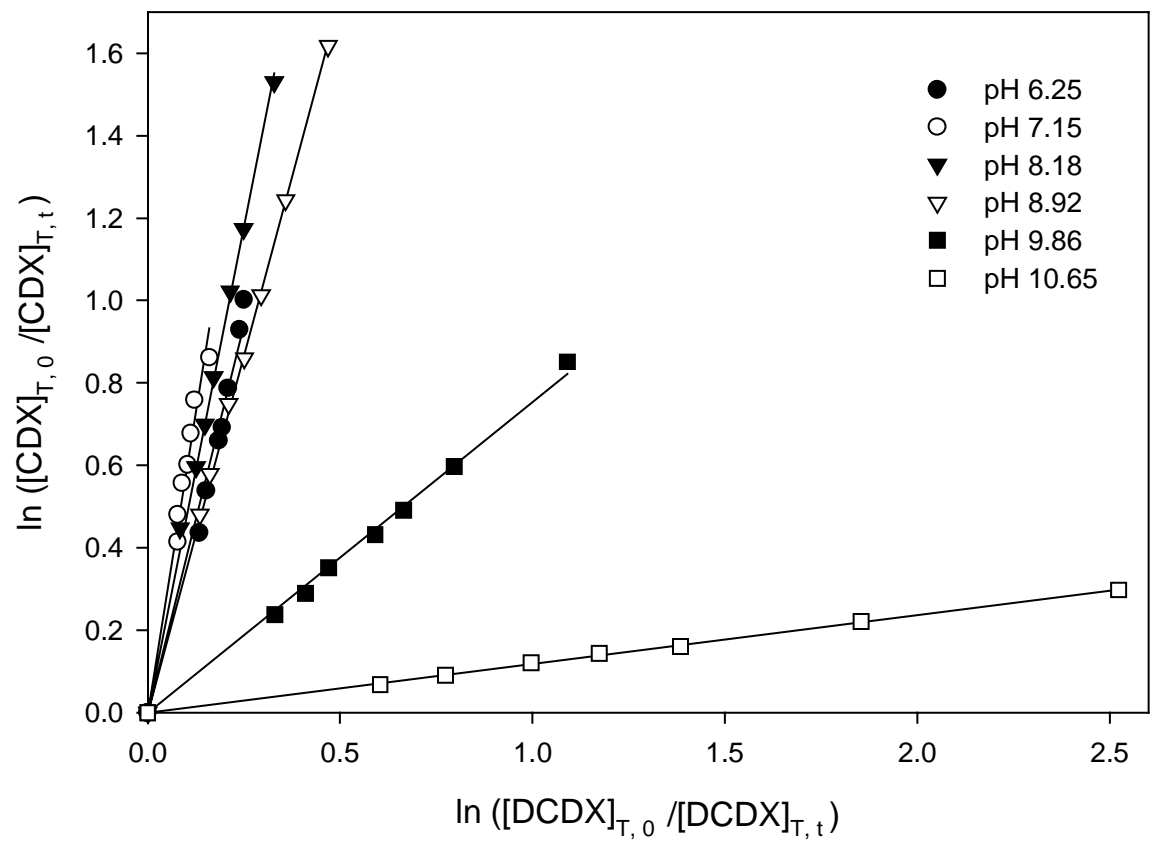


Figure S3. Model $k_{\mathrm{app}}^{\mathrm{CDX}}$ fittings with varying $k_{1}$.

(i) The model fitting curve for $k_{1}=535 \mathrm{M}^{-1} \mathrm{~s}^{-1}$ was obtained by using eq. 4 and initially inputting in non-specific values for $k_{1}$ and $k_{3}$ into the described fitting tool.

(ii) The model fitting curve for $k_{1}=10-250 \mathrm{M}^{-1} \mathrm{~s}^{-1}$ obtained by using eq. 4 and initially inputting in non-specific values for $k_{1}$ and $k_{3}$ into the described fitting tool. In this case $k_{1}$ was bounded, and the output value $\left(k_{1}=10-250 \mathrm{M}^{-1} \mathrm{~s}^{-1}\right)$ always equaled the set boundary condition.

(iii) The model fitting curve for $k_{1}=0 \mathrm{M}^{-1} \mathrm{~s}^{-1}$ obtained by using eq. 5 .

For all model fittings from $k_{1}=0-535 \mathrm{M}^{-1} \mathrm{~s}^{-1}, k_{3}$ and $\mathrm{r}^{2}$ values varied only slightly from $6.00 \times 10^{6}$ $6.02 \times 10^{6} \mathrm{M}^{-1} \mathrm{~s}^{-1}$ and $0.980-0.981$, respectively.

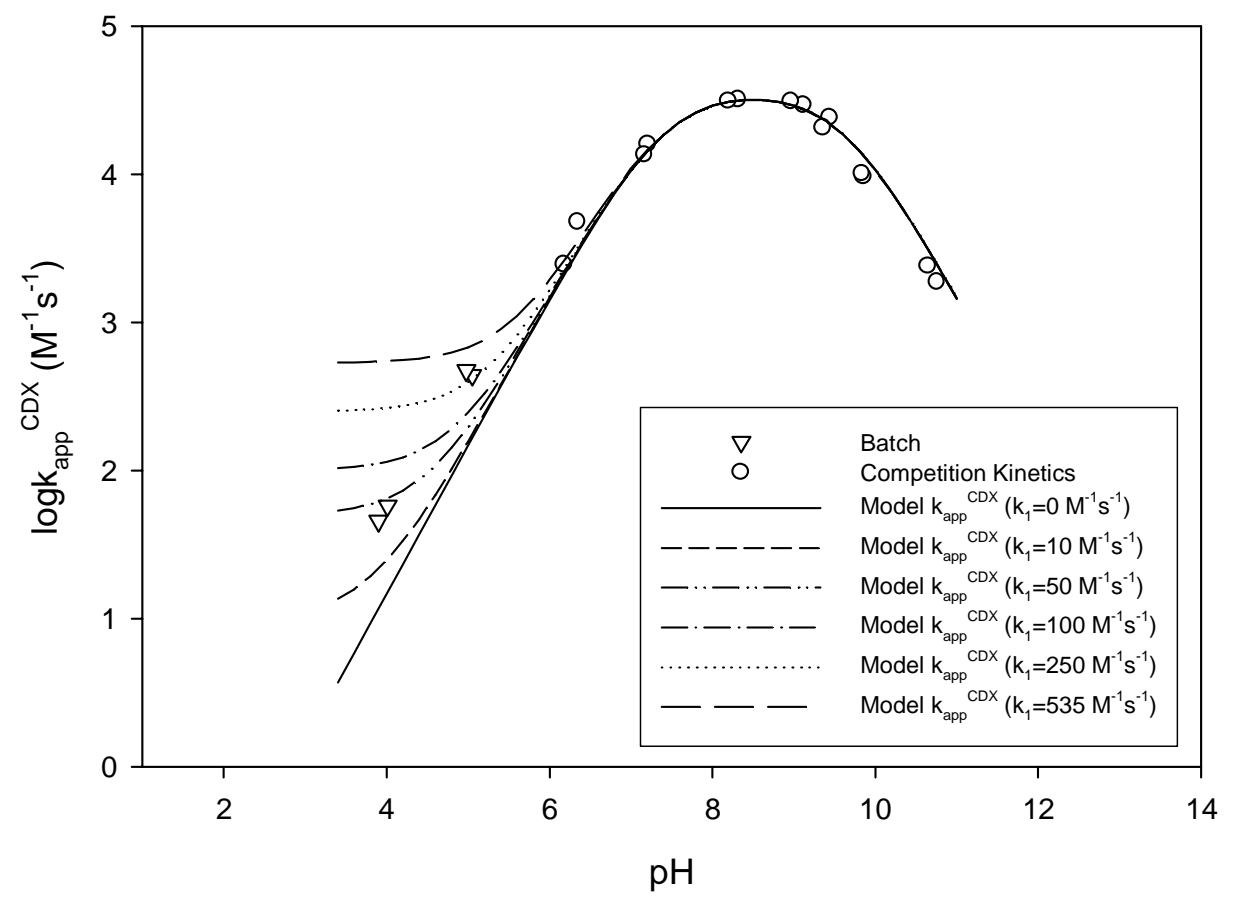


Figure S4. Mass spectra and structures of CDX chlorination by-products (ESI+, $220 \mathrm{eV}$ ), (a) $\mathrm{m} / \mathrm{z} 321$ (M+58) (M, (b) m/z 279 (M+16), (c) m/z 261 (M-2), (d) $m / z 293$ (M+30), (e) $m / z 205$.
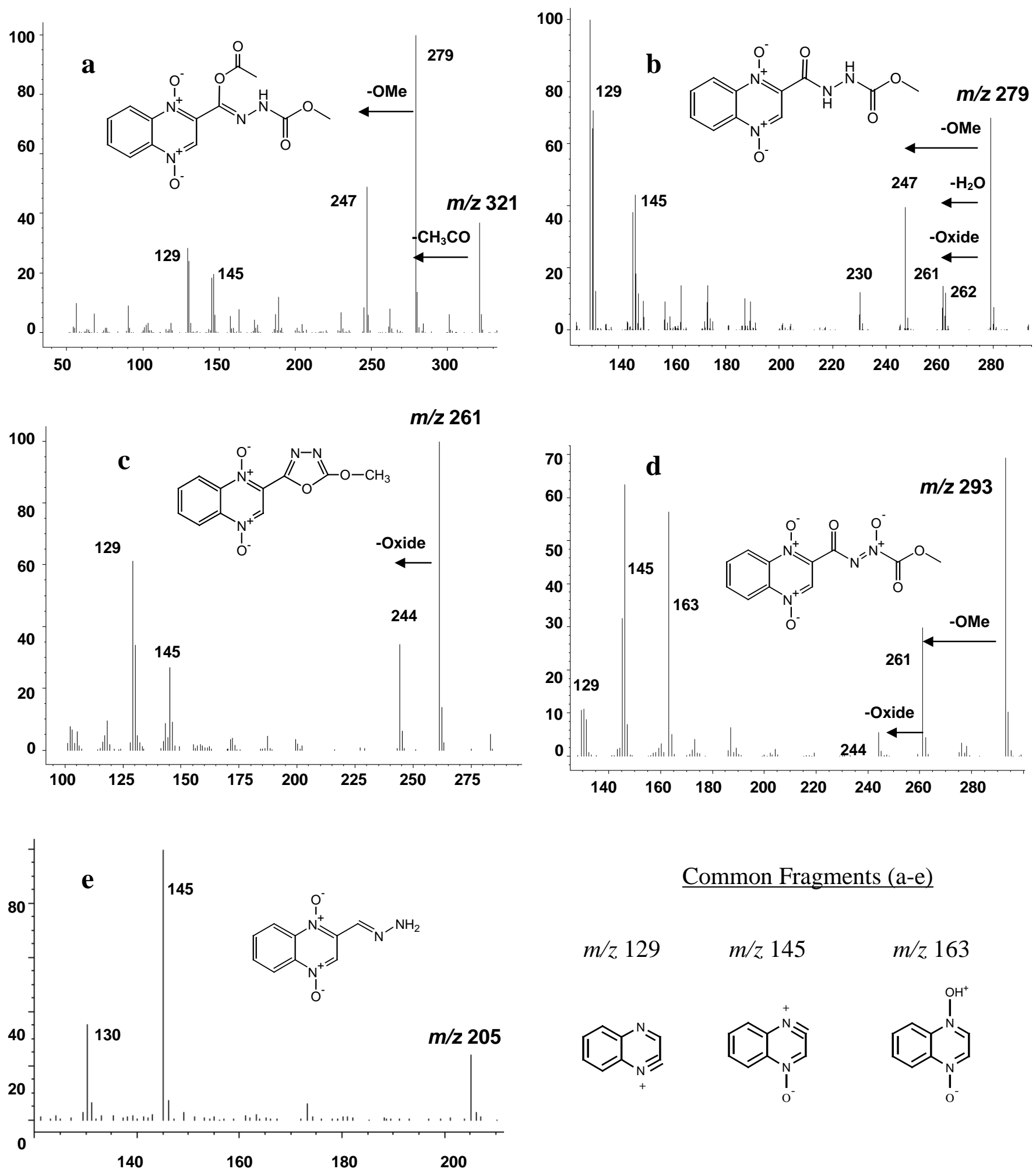

\section{Common Fragments (a-e)}

$m / z 129$

$m / z 145$

$m / z 163$<smiles>c1cnc2ccncc2c1</smiles><smiles></smiles><smiles>COn1ccc2ccccc21</smiles> 
Figure S5. Mass spectra and structures of DCDX chlorination by-products (ESI+, $220 \mathrm{eV}$ ), (a) $\mathrm{m} / \mathrm{z}, 289$ (M+58), (b) $m / z 247$ (M+16), (c) $m / z 229$ (M-2), (d) $m / z 261$ (M+30), (e) $m / z 189$, (f) $m / z 175$ (80 eV).

\section{Common Fragments (a-f)}
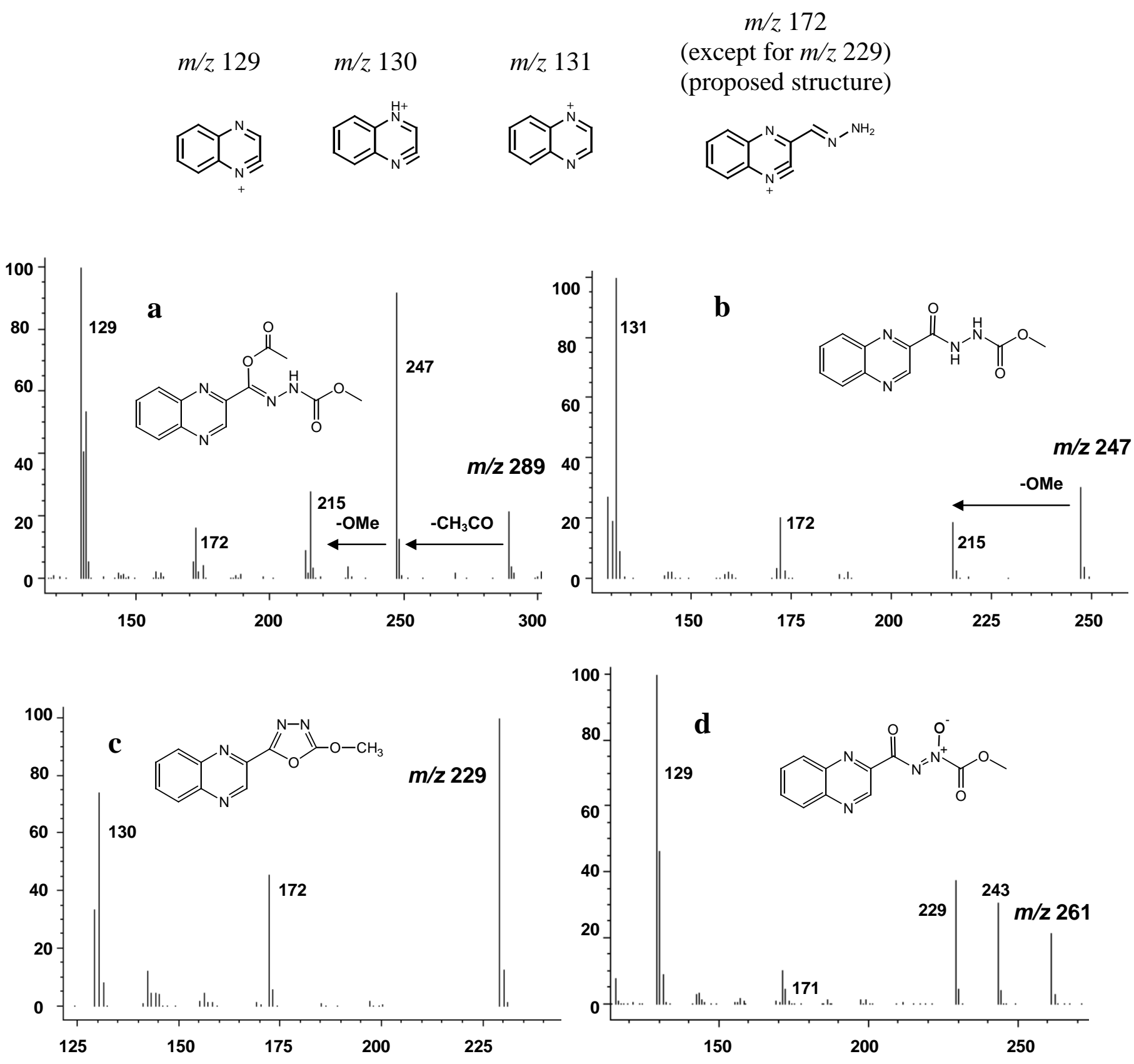

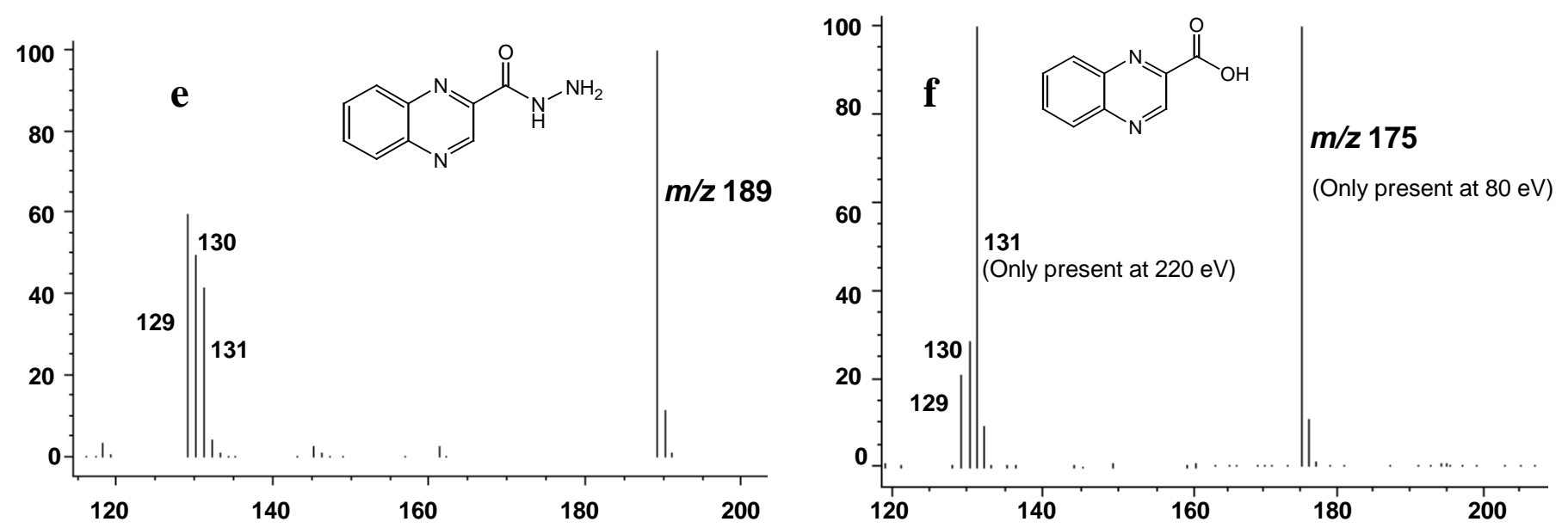
Figure S6. DCDX product evolution under excess free chlorine conditions at $\mathrm{pH}$ 5.2, 7.5, and 8.9 at $25^{\circ} \mathrm{C}$. DCDX rapidly decayed in $<10 \mathrm{~s}$ for $\mathrm{pH} 7.5$ and 8.9. A/ $\mathrm{A}_{\mathrm{MAX}}$ represents the total MS ion counts of each species (DCDX and products) (A) divided by the total ion counts of DCDX at $t=0 \mathrm{~s}\left(\mathrm{~A}_{\mathrm{MAX}}\right)$
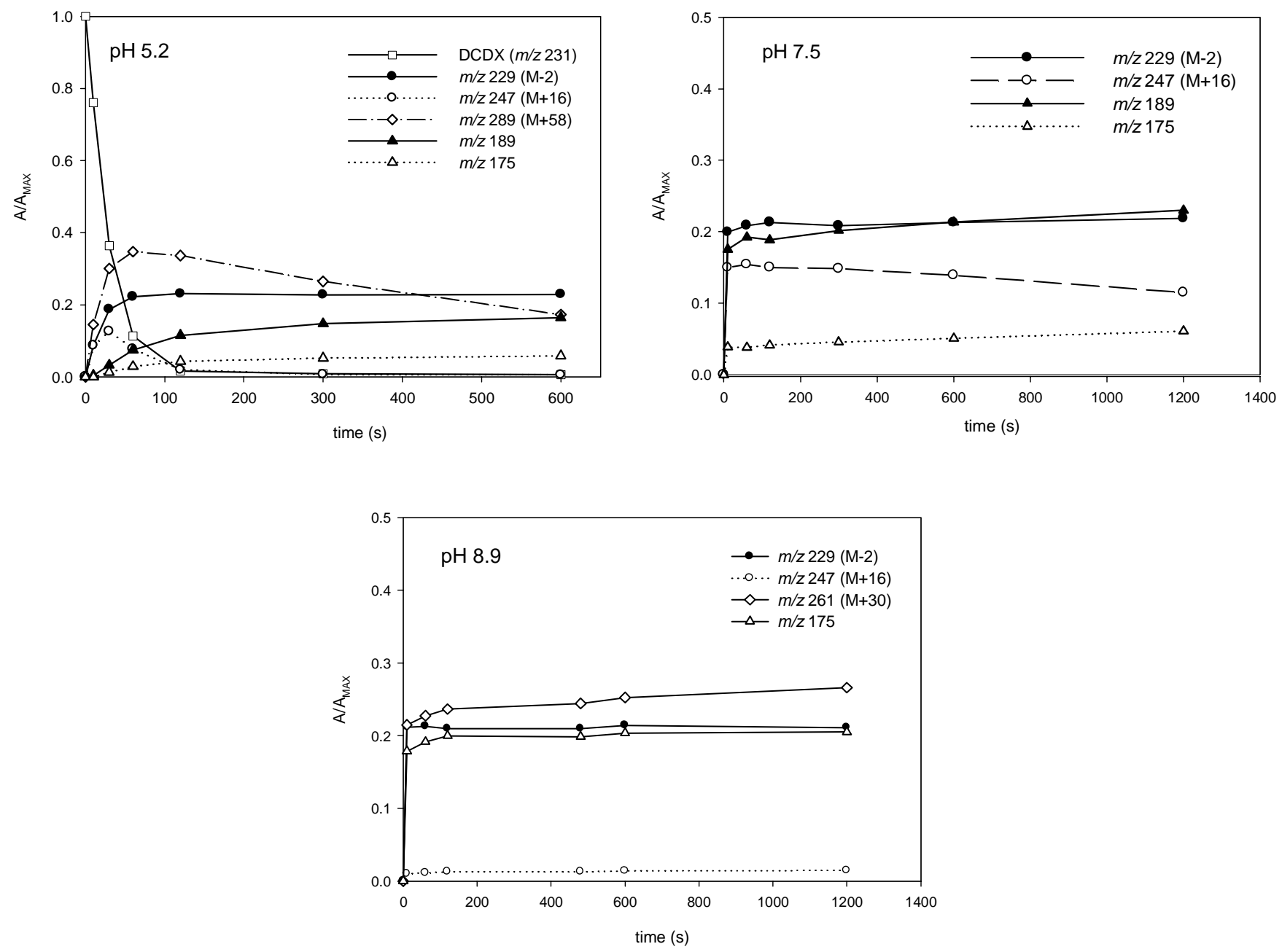
Figure S7. Results below indicate by-products formed after addition of acetate buffer into reaction matrix. Experimental conditions are as follows: $[\mathrm{CDX}]_{\mathrm{i}}=20 \mu \mathrm{M}$, [free chlorine $]_{\mathrm{i}}=20 \mu \mathrm{M}$, reaction time $=4-5 \min , 25^{\circ} \mathrm{C}$, acetate buffer $(\mathrm{pH} 5)=50 \mathrm{mM}, \mathrm{pH}=5.04$.

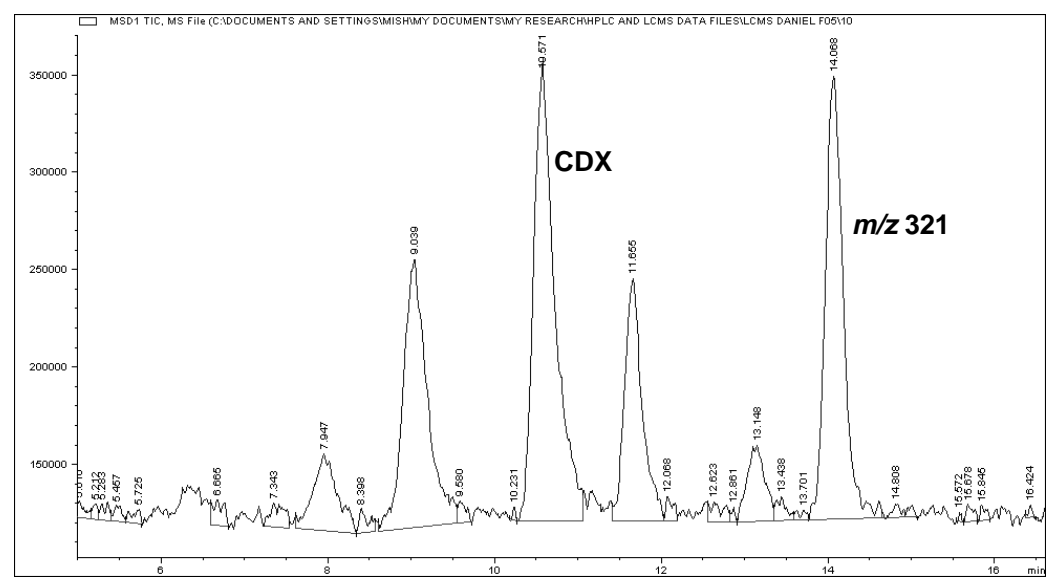

Results below indicate by-products formed with no addition of acetate buffer into reaction matrix.

Experimental conditions are as follows: $[\mathrm{CDX}]_{\mathrm{i}}=20 \mu \mathrm{M}$, [free chlorine $]_{\mathrm{i}}=20 \mu \mathrm{M}$, reaction time $=4-5$ $\min , 25^{\circ} \mathrm{C}, \mathrm{pH}$ adjusted to 4.98 by $\mathrm{HCl}$ addition.

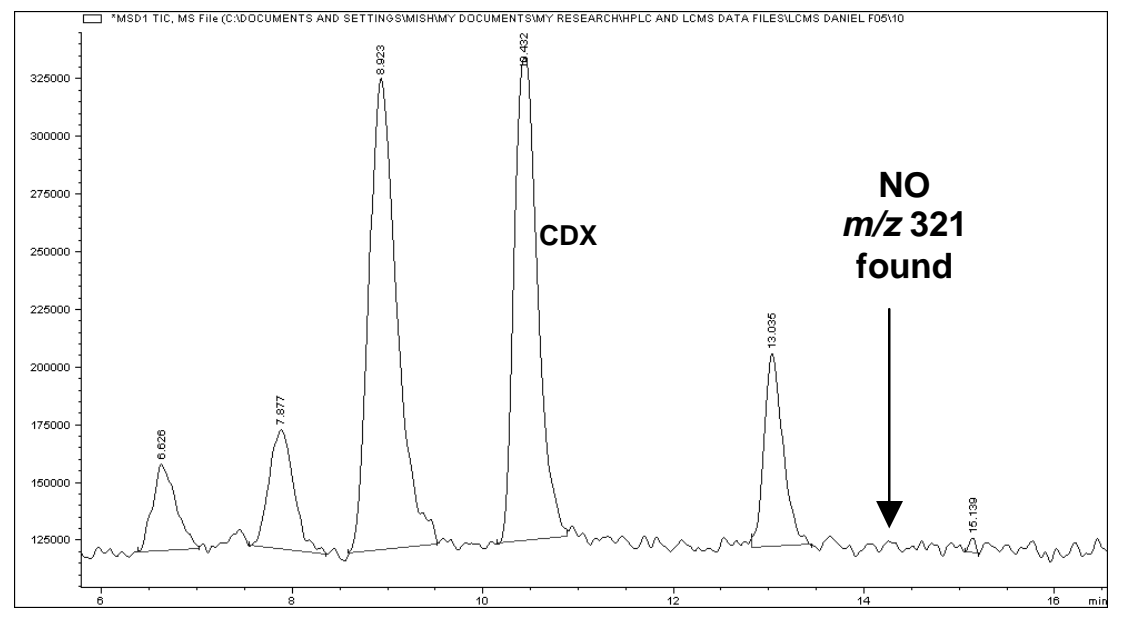


Figure S8. Results below show chlorinated by-product formed upon addition of $\mathrm{NaCl}(50 \mathrm{mM})$ at $\mathrm{pH}$ 4.92. Experimental conditions are as follows: $[\mathrm{CDX}]_{\mathrm{i}}=20 \mu \mathrm{M}$, [free chlorine $]_{\mathrm{i}}=20 \mu \mathrm{M}$, reaction time $=\sim 10 \min , 25^{\circ} \mathrm{C}$, no buffer added, $\mathrm{pH}$ adjusted with $\mathrm{HCl}$ and $\mathrm{NaOH}, \mathrm{pH}=4.92$.
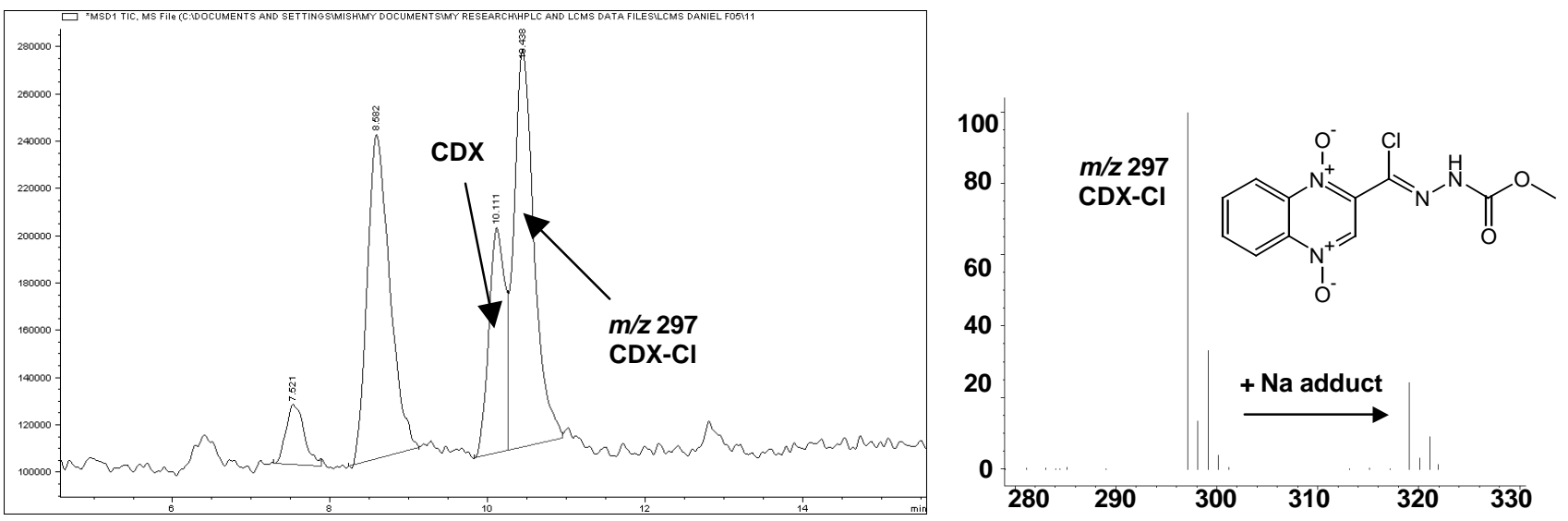

\section{References}

(1) Zhang, H.; Huang, C.-H. Reactivity and transformation of antibacterial $N$-oxides in the presence of manganese oxide. Environ. Sci. Technol. 2005, 39, 593-601.

(2) Standard Methods for the Examination of Water and Wastewater, 20 $0^{\text {th }}$ ed; APHA, AWWA, WPCF: Washington, DC, 1998. 